history. I have been unable to find any tendency to return a second time to a marine life in our living river mussels."

In speaking of the changes taking place in the Baltic Sea, Mr. Findon remarked that the sea was "becoming more shallow, and consequently the communication with the North Sea between the Danish Islands is less free than formerly. On the other hand, the drainage of the marshes of Petrograd has allowed more fresh-water to flow into it; thus there is less influx of salt-water at high tides, and the Baltic is becoming brackish. Indeed, the northern portion is almost fresh, and fiuviatile shellfish have invaded the open water. Many well-known species of the seashore, on the other hand, have held their ground, and we have the phenomenon of salt-water species, such as mussels, cockles, and tellens with a periwinkle, Littorina rudis, the estuarine Mya arenaria, or gaper, and a small univalve, Hydrobia balthica, living in fellowship with the river mussel Unio, two pond snails, Limnæa and Bythinia, the fresh-water Neritina, and a small bivalve, Sphærium. The assemblage is a remarkable one, considering the normal habitat of each of these species, and thus in the Baltic to-day the Lamarckian theory of modification to, but not by, environment, is well illustrated by these marine species, which are gradually changing their salt-water habitat for a fresh-water one."

A paper was read by $\mathrm{Mr}$. Edward A. Martin on Brighton's lost river, in which the gradual disappearance of this river, which at one time flowed out at the Steine Gap, was traced. The river must have been of some importance in prehistoric times, although in historical times its whole history is one of decadence and almost complete disappearance. From a consideration of other rivers on the south coast Mr. Martin endeavoured to build up a former condition of things, which enabled the old town of Brighthelmstone to be built on alluvial flats beneath the cliffs.

"When the Brighton river was in its prime, there is every reason to think that its action was the same as that which now characterises other rivers on the south coast. The flow of the water would bring down with it large quantities of sediment, and bars would be produced at its entrance into the sea. As these increased, alluvial flats would be formed. This, of course, was in pre-history. There were no harbour commissioners to remove the bar. Man had no interest in it. It may have been before his time in these parts. A delta was in process of formation, and would no doubt have been perfected, had not a rival power interfered. The formation of the Brighton delta was influenced at all times by the tidal rise, and this would have been increased on the forcing of the strait of Dover. The river acting in a north to south direction, and the tides acting in a west to east direction, brought about a combination of forces which caused the alluvial drift to move in a more or less easterly direction. There is every reason. to believe that somewhere, a mile or more out at sea, the river was turned to the east by the tides, and that the river was bounded by an alluvial bank formed by the sediment brought down by the river, reinforced by the supply of gravel brought from the west, as it is now, by the tides. What has taken place at Shoreham, Newhaven, and Seaford, took place at Brighton, and I imagine that the Brighton river passed away towards the east below the cliffs for some distance, dropping its sediment on the way, before it was able to force and keep open its outlet into the sea. Lyell mentioned that in the reign of Elizabeth "the town was situated on that tract where the Chain Pier now extends into the sea.'

"In the course of centuries the river became deprived of its excavating power, and many of its feeders were captured, so that the body of water flowing down became seriously lessened. The process was a slow one, but sooner or later the struggle with the tides proved an unequal one. Hitherto, all that the tides could do was to turn the river eastward and enclose it within a long, low-lying bank of shingle, and the denuding power of the wind and storm waves, raised on the shoulders of the tidal rise, was at a minimum. When the entrance of the considerable body of opposing water from the valley was modified, and the influence it possessed practically ceased, alluvium ceased to be deposited, and the denudation of the alluvial ground-covered flat and its destruction by the sea commenced. This went on unceasingly, until the whole of the land beneath the cliffs was washed away. Mantell remarks that "the whole of the ancient town was situated on a spot now covered by the sands,' whilst Lyell mentions that 'the sea has merely resumed its position at the base of the cliffs, the site of the old town having been a beach which had for ages been abandoned by the ocean.' The old town had, as a matter of fact, been built on the alluvial flats which had been laid down by Brighton's lost river."

Discussion on the origin of the Brighton RubbleDrift Formation in the Kemp Town cliffs elicited the fact that in addition to the palæofith from the raised beach (now at the British Museum), another implement of Chellean form has been obtained from the raised beach at Slindon, near Arundel, West Sussex.

Other papers read were by Prof. G. S. Boulger, on Kew : some notes on its connection with the history of botany; by Mr. A. Bonner, on the study of placenames; by Mr. A. W. Oke, on three Sussex worthies: Mantell, Robertson, and Jefferies; and by Mr. C. C Fagg, on regional surveys and local natural history societies. Excursions to points of interest in the district were made during the congress, which, in spite of many difficulties, was carried through in a very successful manner.

\section{OSMOTIC PRESSURE AND THE PROPERTIES OF SOLUTIONS.}

TWO monographs dealing with the properties of solutions have recently been issued by the. Carnegie Institution of Washington. The first, entitled "Osmotic Pressure of Aqueous Solutions," is a report by $H . N$. Morse, on the investigations made in the chemical laboratory of the Johns Hopkins University during the years $1899-1913$. This masterly investigation, extended already over a period of fifteen years, has been recognised at once, and universally, as one of the classics of scientific literature. As the substance of the investigation was originally issued in more than a score of papers, it is a great advantage to have the whole work summarised, corrected, and brought up to date by the author himself. The whole technique is now set out in a series of chapters dealing with the cells and manometer attachments; the manometers; the regulation of temperature; and the membranes. The fifth chapter contains a strong defence of the weight-normal system for solutions against criticisms and attacks that have been made upon it,-arising mainly from the mistaken assumption that this method of working was the expression of some theoretical view of the nature of solutions or the mechanism of osmotic pressure.

The opinion is emphatically put forward that a comprehensive equation for the osmotic pressures of solutions can only be reached by means of experiments,. and that so many phenomena are involved that it will be impossible to predict the osmotic pressure of a solution unless the magnitude of some of

NO. 2382 , VOL. 95] 
these, such as the hydration of the solute, have been determined by direct measurements made with the solution itself. Nevertheless, when the solutions are made up to equal weights of solvent. instead of to equal volumes of solution, and when the volume used for calculation is the volume of the solvent used in making the solution, it has been found that the ratio of osmotic pressure to gas pressure falls to unity at $30^{\circ} \mathrm{C}$. in a decinormal, and at $80^{\circ} \mathrm{C}$. in a normal solution of cane-sugar. At lower temperatures, the ratio is greater than. unity, probably on account of the formation of hydrates.

A similar remarkable agreement has been obtained in a final. series of measurements, made under the most highly perfected experimental conditions, of the osmotic pressure of solutions of glucose at $30^{\circ}, 40^{\circ}$, and $50^{\circ} \mathrm{C}$. Twenty-four measurements are recorded, in which the average value of the ratio of osmotic pressure to gas pressure was exactly $\mathbf{r} \cdot 000$, and the average error less than $\pm 0.00 I$. In the case of mannitol at five or six concentrations, and at temperatures from $10^{\circ}$ to $40^{\circ}$, the average ratio was $\mathrm{x} \cdot 00 \mathrm{O}_{5}$, and the average error $\pm 0.00 I_{5}$, showing that within the limits thus far investigated, aqueous solutions of mannitol obey the laws of Gay-Lussac and Boyle.

The volume concludes with a preliminary account of some experiments on the osmotic pressure of electrolytes, which do not appear to have been published hitherto in any of the scientific journals. Potassium chloride (half-normal), barium chloride, and potassium ferrocyanide caused a rapid degeneration of the membrane, prokably due to the destruction of its colloidal character. The degeneration was progressive, and could not be remedied by long soaking in water. Lithium chloride rendered the membranes very sluggish, but they retained their semi-permeability up to a concentration of 0.6 normal; a solution of this concentration was observed over a period of one hundred days, the average osmotic pressure for the whole period being 18.789 atmospheres, and for successive groups of twenty days, 18.827, 18.894, 18.799, 18.636 , and 18.405 . The ratios of osmotic pressure to gas pressure at $30^{\circ}$ were as follows :-

$\begin{array}{lllllll}\text { Concentration } & 0.1 & 0.2 & 0.3 & 0.4 & 0.5 & 0.6 \\ \text { Ratio } & \mathrm{I} \cdot 746 & \mathrm{I} \cdot 8 \mathrm{I} 6 & \mathrm{I} \cdot 857 & \mathrm{I} \cdot 899 & \mathrm{I} \cdot 955 & \mathrm{I} \cdot 99^{2}\end{array}$

This increase in the ratio is entirely opposed to the effects produced by variations of electrolytic dissociation, but may be explained by the diminution of the free water as a result of the formation of hydrates.

This formation of hydrates in solution is a leading feature of the work described in the second monograph, by $\mathrm{H}$. C. Jones and his collaborators. The first section of the monograph receives a separate title, "The Absorption Spectra of Solutions as. Studied by Means of the Radiomicrometer," but its main subject is the influence of hydrated and non-hydrated salts on the absorption of light by water. The chief result is to show that aqueous solutions of hydrated salts generally have greater transparency than pure water at the centres of the absorption-bands. The exceptions are the $I \mu$ band for zinc nitrate and magnesium nitrate and the $\mathbf{I} \cdot 25$ band for magnesium nitrate. Nonhydrated salts, under similar conditions, give results in many respects exactly the opposite of those obtained with hydrated salts. The remainder of the monograph deals with "The Conductivities, Dissociations, and Viscosities of Solutions of Electrolytes in Aqueous, Non-aqueous, and Mixed Solvents." The chief solvents used were water, ethyl alcohol, ethyl alcohol and water, acetone and water, and ternary mixtures of glycerol, acetone, and water. The final chapter, covering nearly sixty pages, is devoted to a "Dis- cussion of Evidence on the Solvate Theory of Solution obtained in the Laboratories of the Johns Hopkins University." This summary extends from the time when, as the author says, "In the summer of 1893 I went to Stockholm to work with Svante Arrhenius," and extends to the present day. It deals with the work which has appeared in eighty papers, widely scattered through chemical and physical literature, and published in American, German, French, and English scientific journals, in addition to nine monographs already published by the Carnegie Institution of Washington. It is to the support of this institution that the present wide extension of these investigations is largely due.

T. M. L.

\section{ELECTRONS AND HEAT.1}

WHEN electrified bodies are heated they are found to lose the power of retaining an electric charge. The charge leaks away from their surfaces. This is not a novel phenomenon. It has been known for nearly two centuries that solids glowing in air are capable of discharging an electroscope. Thus you observe that the electroscope is at once discharged when I bring near it a red-hot poker withdrawn from the furnace on the lecture table. These effects are due to the emission of ions by the hot solids. For example, if the electroscope is negatively charged it draws positive ions from the hot poker and so becomes discharged.

Most bodies when heated in air at low temperatures emit only positive ions. At sufficiently high temperatures ions of both signs are emitted simultaneously. We can show this by a simple experiment in which the hot body consists of a loop of platinum wire and acts as its own electroscope. When a charged rod is brought near the loop a charge of opposite sign is induced on the latter, which is thus deflected owing to the electrostatic attraction of the rod. When the loop is cold this happens whatever the sign of the charge on the rod. If the wire is at a dull red heat it can only be deflected by a positively charged rod. When a negatively charged rod is brought near. it the emission of positive ions causes the induced positive charge at once to stream away. Thus the wire is incapable of retaining a positive charge, and so no deflection is produced by a negatively charged rod. At very high temperatures you observe that the loop is undeflected whatever the sign of the charge on the rod. The wire is now liberating both positive and negative ions, and so is unable to retain either a positive or a negative charge.

If these effects are investigated in a vacuum, instead of in air at atmospheric pressure, it is found that the emission of positive ions gradıally disappears with continued heating, so that a wire which has been well glowed out in a vacuum emits only negative ions in appreciable quantity. Thus if we repeat the last experiment with an incandescent lamp, using one in which the filaments are not anchored, we see that the loops are attracted by a negatively charged rod, but not by one which is charged positively. They show, in fact, a behaviour which is precisely opposite to that of a wire at a dull red heat in air.

Now let us consider the nature of the ions which carry these thermionic currents, to use a term which I have ventured to apply to the currents which leak away from the surfaces of hot bodies in this manner. As is well known, the negative electrons which play such an important part in physical phenomena are very readily deflected by moderate magnetic fields, whereas ions of atomic or greater magnitude are not.

1 Discourse delivered at the Royal Institution on Friday, May $;$, by Prof. O. W. Richardson, F.R.S.

$$
\text { NO. 2382, VOL. } 957
$$

